\title{
EL VIENTO DEL SUDOESTE: PROLEGÓMENOS DE \\ UNA TESIS LATINOAMERICANA SOBRE LA \\ LÓGICA DE LA GUERRA FRÍA. UN ENSAYO \\ SOBRE SOLIDARIDAD REGIONAL Y OPOSICIÓN \\ AL INTERVENCIONISMO
}

Carlos Federico Domínguez Avila ${ }^{1}$

\begin{abstract}
"No admitimos los fundamentos doctrinários de la guerra fría, ni nos dejamos caer en sofismas elementales. Sabemos que en éstas cruzadas los débiles acaban sustentando siempre, a costas de su evolución, el incesante crecimiento de los más poderosos."

Presidente Miguel de la Madrid Hurtado

(Brasilia, marzo de 1984)
\end{abstract}

\section{Introducción}

El propósito de este artículo es contribuir para revitalizar el debate sobre el impacto y la reacción de los pueblos y gobiernos de América Latina y el Caribe frente a la lógica y políticas propias de la así llamada Guerra Fría. En esa línea, se procura abordar la relación América Latina y el Caribe-Guerra Fría sobre la base de la llamada teoría de las superpotencias o del conflicto Norte-Sur.

Conviene agregar que la imagen de "viento del sudoeste" se inspira en la famosa frase de Mao Zedong, de 1957, cuando afirmó: "Existen dos vientos en el mundo actual; el viento del Este y el viento del Oeste; [...] Pienso que la característica de la situación actual es el viento del Este prevaleciendo sobre el viento del Oeste" (citado en

\footnotetext{
${ }^{1}$ Doutor em história das relações internacionais pela Universidade de Brasília (2003) e professor do curso de Relações Internacionais do CEUB.
}

Universitas - Relações Int., Brasília, v. 2, n.2, p. 137-167, jul./dez. 2004 
LaFeber, 1991: 199). Siguiendo la metáfora de Mao Zedong, aqui se sostiene que durante los perturbadores años de la Guerra Fría también existió un "viento" especificamente del "sudoeste" del mundo -quiere decir originado a partir de los pueblos que se identificaban con los problemas y aspiraciones del Sur (naciones en desarrollo) y del Oeste, lo que corresponde principalmente a las naciones latinoamericanas y caribeñas, que son, como se sabe, simultáneamente, occidentales y en desarrollo (Rouquié, 1997). Consecuentemente, la imagen de "viento del sudoeste" alude a una teorización de la política internacional latinoamericana y caribeña frente al contexto específico de la lógica de la Guerra Fría, vigente durante gran parte de la segunda mitad del siglo $\mathrm{XX}$.

Aqui se sostiene que la esencia de la política internacional de los pueblos del "sudoeste" del mundo frente a la -perversa, fatua y empobrecedora- lógica inherente a la guerra fría (1947-1989) habría terminado inspirandose y guiandose por un conjunto más o menos coherente de criterios o ponderaciones documentalmente verificables. A su vez y colectivamente, tales criterios o ponderaciones dan lugar a lo que en el presente estudio se llamará de prolegómenos de la tesis latinoamericana sobre la lógica de la guerra fría.

Nótese que dicho núcleo duro o irreductible de política internacional en alguna medida implicó la revitalización del paradigma bolivariano. Este fundamentado, como se sabe, en la cooperación y solidaridad intra-regional, por un lado, y en la oposición frente al intervencionismo y a las presiones hegemónicas de las grandes potencias mundiales -sobretodo de las superpotencias -, por otro. Conviene agregar que dicho núcleo duro o irreductible de política internacional es una teorización surgida del análisis ponderado de experiencias históricas conocidas y relevantes, tales como: la tercera vía peronista, el no alineamiento mexicano, la así llamada política externa independiente brasileña (especialmente del período QuadrosGoulart), la "doctrina Betancourt", las tesis del subimperialismo, los llamados "internacionalismos" de derecha e izquierda, el pensamiento cepalino, entre otros.

Universitas - Relações Int., Brasília, v. 2, n.2, p. 137-167, jul./dez. 2004 


\section{Hacia una conceptualización de la noción de Guerra Fría}

La así llamada Guerra Fría, que caracterizó en gran medida al orden internacional global entre 1947 y 1989/91, no expresó solamente la confrontación, competencia y tensión entre los "dos imperialismos" (el estadounidense y el soviético), entre los dos más importantes bloques político-militares (OTAN-Pacto de Varsovia) o entre los sistemas sociales antagónicos (capitalismo-socialismo). La guerra fría terminó siendo mucho más que eso. De hecho la lógica y las políticas propias o derivadas de la confrontación soviético-estadounidense también terminaron erigiendo o fomentando fenómenos tales como: a) una subordinación/disciplinamiento de las clases trabajadoras al interior de las propias grandes potencias, siendo que ello redundó en beneficio de los correspondientes sectores dominantes - especialmente de los intereses político-económicos más próximos de los respectivos complejos industriales-militares -; y b) contradicciones más o menos intensas y persistentes entre las superpotencias y sus respectivos aliados y clientes, tanto en el teatro europeo - donde surgieron no pocos conflictos Oeste-Oeste y Este-Este - como en el mundo en vías de desarrollo (conflictos Norte-Sur).

Si la Guerra Fría, en cuanto objeto de estudio propio del campo de la historia de las relaciones internacionales contemporáneas, es encarada como un mecanismo cuyo propósito básico fue la progresiva y simultánea subordinación/disciplinamiento de las clases trabajadoras por y en beneficio de los sectores dominantes de las naciones centrales $\mathrm{y}$, hasta cierto punto, de sus correspondientes "socios", aliados o clientes en otras naciones, especialmente en las naciones en desarrollo, entonces la conceptualización del término debe ser objeto de un proceso de redefinición.

Inicialmente, parece apropiado señalar que la noción de "Guerra Fría" es muy antigua y que, con el correr del tiempo, ha sufrido innúmeras redefiniciones. Anders Stephanson (1996) plantea que dicha noción ya era conocida en la Edad Media. En su opinión, habría sido un noble del Reino de Castilla, Don Juan Manuel, quien, a principios del siglo XIV, utilizó el vocablo para designar el "estado

Universitas - Relações Int., Brasília, v. 2, n.2, p. 137-167, jul./dez. 2004 
natural de guerra entre Cristianos y Musulmanes"; quiere decir, un conflicto más o menos permanente entre doctrinas ideológicas en competencia.

En esa línea, una "guerra fría" puede entenderse en dos sentidos, por un lado, se trata de un conflicto que no es "caliente", puesto que no existen batallas que terminen en victoria o derrota total frente al adversario, y, por ello no ofrecen "ni paz ni honor". Por otro lado, el sentido de una "guerra fría" sugiere que las relaciones entre dos o más actores no son buenas; ésto es, son tensas, amenzadoras y hostiles. En consecuencia, tradicionalmente la noción de "guerra fría" se entendió como "un particular período de conflicto globalizado, en el cual el énfasis es fundamentado en la confrontación militar y estratégica y en el cual la negociación es mínima o no existente" (Halliday, 1986: 9).

Siguiendo a Fred Halliday, desde el fin de la Segunda Guerra Mundial hasta 1989/91, cuando ocurrió el derrumbe del Muro de Berlín y la virtual implosión de la comunidad socialista, uno de los elementos definidores de las relaciones internacionales habría sido la competencia, el proceso de re-bipolarización y la lucha por la hegemonía mundial entre dos sistemas sociales liderados por Washington y Moscú. En su opinión, estos cuarenta años de historia de relaciones internacionales podrían ser divididos en cuatro sub-períodos que él llama: a) Primera Guerra Fría (1947-1953), b) Antagonismo Oscilatorio (1953-1969), c) Détente (1969-1979), y d) Segunda Guerra Fría (1979-1989).

Escenarios de la Guerra Fría. Afirmar que una de las principales características de la Guerra Fría fue su dimensión global implica, entre otras cosas, reconocer que la lógica y las políticas inspiradas en la tensión y competencia Este-Oeste provocaron un impacto más o menos significativo en las relaciones internacionales en la mayor parte del planeta.

En el ámbito político, la tensión internacional se puede estudiar en dos niveles articulados. Por un lado, en las relaciones entre las propias superpotencias y sus respectivas alianzas estratégicas (especialmente, la OTAN y el Pacto de Varsovia). Por otro lado, en los conflictos regionales en el Tercer Mundo.

Universitas - Relações Int., Brasília, v. 2, n.2, p. 137-167, jul./dez. 2004 
En lo que respecta a las relaciones entre las superpotencias, conviene señalar que destacó: (a) la vigorosa competencia hegemónica en distintos foros internacionales y europeos; (b) la guerra propagandística; (c) la persistente carrera de armamentos; (d) la parálisis en las negociaciones multilaterales y bilaterales, particularmente, aquellas sobre control y verificación de armas nucleares; entre otras ponderaciones. Todo ello sugiere que las relaciones entre Washington y Moscú realmente eran conflictivas e incluso antagónicas (LaFeber, 1991).

En el mundo en desarrollo, muchos conflictos socio-políticos internos e internacionales pre-existentes adquirieron la lógica EsteOeste cuando las superpotencias consideraron que intervenir era conveniente para potenciar sus respectivos intereses estratégicos y/o cuando actores endógenos apelaron a la ayuda de alguno de los bloques en competencia. De ese modo, el sesgo ideológico socialismocapitalismo transformó a numerosos conflictos internos (e incluso tribales) en sangrientos escenarios de la Guerra Fría. Surge, así, la noción de conflicto regional en el Tercer Mundo, que es sumamente importante para los fines de la presente investigación histórica.

El término conflicto regional en el Tercer Mundo se entiende como una situación de aguda tensión y conflicto armado generado por la interacción compleja entre factores locales (y sub-regionales), por un lado, e influencias, aspiraciones y presiones hegemónicas extraregionales, por otro. Siendo que la interacción entre presiones endógenas y exógenas amenazó con comprometer el envolvimiento de las dos superpotencias de la época, los Estados Unidos y la Unión Soviética, sea directamente o indirectamente a través de sus respectivos aliados. Por tanto, un conflicto regional supone la "internacionalización" o "globalización" de una crisis local o subregional, a través de la articulación de factores esencialmente endógenos con presiones y aspiraciones hegemónicas de potencias continentales y globales.

En el ámbito económico, la lógica del conflicto Este-Oeste se expresó en la intensificación de las divergencias entre doctrinas de economía política y la propaganda de los respectivos modelos de desarrollo socio-económico. Por un lado, Washington, Londres y

Universitas - Relações Int., Brasília, v. 2, n.2, p. 137-167, jul./dez. 2004 
algunos de los más importantes organismos financieros internacionales (Fondo Monetario Internacional, Banco Mundial) promovian la implementación de economías liberales de mercado. Entretanto, Moscú y otros países socialistas destacaban las virtudes de la economía de planificación centralizada con amplio predominio del sector público.

Vale agregar que el conocido modelo cepalino de "desarrollo hacia adentro" -utilizado, desde el decenio de 1930, en algunos países de América Latina y el Caribe para promover la industrialización y el crecimiento económico - también fue objeto de la disputa ideológica. Por un lado, era positivamente evaluado por los soviéticos, al considerarlo como un ejemplo de modelo de desarrollo dirigido por el Estado. En contraste, el mismo modelo fue duramente cuestionado por economistas y políticos de orientación neo-liberal inspirados en los trabajos de Friedrich von Hayek, Milton Friedman y Michael Novak, en los llamados Reaganomics, y, muy particularmente, en el llamado Consenso de Washington - surgido a comienzos del decenio de 1980 para enfrentar la grave crisis del endeudamiento externo latinoamericano desde la perspectiva del modelo de economía liberal de mercado.

En el ámbito estratégico, Washington y Moscú se dieron la tarea de crear, modernizar, reforzar y disciplinar las respectivas alianzas estratégicas y acuerdos militares con aliados en el Tercer Mundo. Para varios autores, los intentos de las superpotencias para (re)imponer la hegemonía en tales pactos militares (particularmente, la OTAN y el Pacto de Varsovia) provocó no pocos conflictos OesteOeste y Este-Este.

Conviene agregar que, hacia fines del decenio de 1980, ocurrieron importantísimas mutaciones estratégicas -con destaque para el derrumbe del Muro de Berlín y la reunificacion de Alemania- que marcaron el agotamiento total de la alianza militar impuesta por los soviéticos en Europa Oriental y un evidente debilitamiento del poder y la posición de la Unión Soviética (y luego, de Rusia) en el sistema internacional. Al menos en el teatro europeo, el derrumbe del Muro de Berlín y la posterior implosión del bloque soviético terminó marcando el fin de la (Segunda) Guerra Fría y la apertura de un nuevo período en la historia de las relaciones internacionales contemporáneas.

Universitas - Relações Int., Brasília, v. 2, n.2, p. 137-167, jul./dez. 2004 
Asimismo, parece importante destacar que América Latina y el Caribe en general, y la cuenca del Caribe en particular, también fue un escenario importante en el contexto de la Guerra Fría. Los conflictos inspirados en la lógica y las políticas de la Guerra Fría fueron muy evidentes en Guatemala (1954), Cuba (desde 1960), República Dominicana (1965), Chile (1970-1973), Nicaragua (1980-1990), El Salvador (1980-1992), Granada (1980-83), y en menor medida y con otras características en Haití, Honduras, Perú, Costa Rica, México, Suriname, Brasil, Guyana, Colombia, Venezuela, Jamaica, Chile, Argentina, etc. Posiblemente lo más expresivo de la reacción de las naciones latinoamericanas y caribeñas frente a las -espurias, antijurídicas e inmorales- aspiraciones y presiones hegemónicas de las superpotencias fue la resistencia y oposición a las mismas, así como la revitalización del diálogo y la solidaridad intra-regional.

Hacia una matriz disciplinaria para la historia de la Guerra Fría. La así llamada Guerra Fría refiere a un período extremadamente complejo en la historia de las relaciones internacionales contemporáneas debido, fundamentalmente, a la particular articulación de variables propias de la política internacional con otras variables de naturaleza económica, sociopolítica, ideológica, militar, ambiental, etc. Al mismo tiempo, el carácter multifacético, dinámico y denso del proceso histórico en el período permite que la Guerra Fría pueda ser estudiada por investigadores desde diferentes, y a menudo antagónicas, posiciones teórico-metodológicas.

Dichas posiciones teórico-metodológicas, a las que también es posible llamar "paradigmas" -en el sentido kuhniano del término-, permiten construir una "matriz disciplinaria" -entendida como campo de tensión epistémica entre paradigmas activos y en competenciapropia para el estudio de los problemas planteados por la lógica y las políticas inspiradas en la Segunda Guerra Fría. Aceptando el riesgo de parecer reduccionista o demasiado esquemático, es posible identificar al menos cinco paradigmas o posiciones teórico-metodológicas básicas que forman parte de la matriz disciplinaria específica para el estudio de la historia de la Guerra Fría ${ }^{2}$ :

2 Vale notar que la mayoría de las posiciones teórico-metodológicas fueron eventualmente utilizadas por gobiernos $\mathrm{u}$ organizaciones de diferente naturaleza

Universitas - Relações Int., Brasília, v. 2, n.2, p. 137-167, jul./dez. 2004 
(a) Teoría de la Contención del Expansionismo Soviético. Originalmente planteada por George Kennan, en un famoso artículo publicado en 1947, los teóricos y formuladores de política exterior inspirados en esta doctrina sostienen que desde el triunfo de la Revolución Rusa, en 1917 y, sobretodo, a partir de 1945, la política exterior soviética se habría caracterizado por una estrategia de largo plazo destinada a derrocar las sociedades capitalistas del mundo y reemplazarlas con régimenes comunistas. En ese sentido, la política exterior de Washington -y de otros países del así llamado Mundo Libre- debería caracterizarse por una persistente "contención" de las atribuidas aspiraciones expansionistas de la élite revolucionaria soviética y de sus aliados y clientes en todo el mundo. Desde esta perspectiva, las graves tensiones internacionales serían consecuencia de la agresividad, expansionismo y aventurerismo de la Unión Soviética y de sus aliados, particularmente intenso durante la segunda mitad del decenio de 1970 (Rodman, 1994). Nótese que, desde la óptica de la Casa Blanca, el "expansionismo" soviético se reflejaba claramente en los avances revolucionários en el Tercer Mundo. En consecuencia, Estados Unidos y otros países de Occidente habrían de implementar, especialmente durante el decenio de 1980, una renovada política de contención del expansionismo soviético que cristalizó en la adopción un enfoque (neo)globalista de la política exterior, que incluyó la llamada "doctrina Reagan" y sus rollback policies. $^{3}$

como plataformas doctrinales para justificar determinadas decisiones de carácter político, económico, estratégico, etc. En ese sentido, la matriz disciplinaria permite apreciar el árduo debate de ideas e ideologías entre intelectuales orgánicos con intereses particulares en un contexto general de gran tensión internacional.

${ }^{3}$ En términos operativos la así llamada doctrina Reagan implicaba, entre otras cosas, el abierto apoyo diplomático, financiero y militar a grupos y organizaciones paramilitares anti-comunistas que luchaban contra régimenes "tendientes al socialismo" instaurados principalmente en el marco de la Tercera Ola Revolucionaria en el Tercer Mundo. En éste sentido, la intención declarada de Washington era revertir o hacer retroceder gobiernos "progresistas", "anti-imperialistas" o simplemente "hostiles" (Afganistán, Angola, Cuba, Etiopía, Granada, Irán, Laos, Kampuchea, Nicaragua, Mozambique, Suriname, Vietnam, Yemen del Sur, etc.) mediante una mezcla de presión diplomática, económica, ideológica y militar (roll back policies).

Universitas - Relações Int., Brasília, v. 2, n.2, p. 137-167, jul./dez. 2004 
(b) Teoría del Imperialismo. En gran medida es el inverso de lo anterior al plantear, en términos generales, que las graves tensiones que caracterizaron a la Guerra Fría se explicarían por la agresividad del imperialismo estadounidense, en una fase de declinio en su poder hegemónico en el mundo capitalista. En otras palabras, los intelectuales inspirados en la Teoría del Imperialismo, la que por cierto tiene entre sus fundadores a conocidos autores como Hobson y Lenin, sugieren que la confrontación internacional se debió principalmente - a la reacción negativa de los grupos dominantes particularmente los segmentos neo-conservadores - en Estados Unidos, el Reino Unido y otros países occidentales frente a los avances en los procesos de liberación nacional en el Tercer Mundo, la creciente capacidad estratégica de los soviéticos y el persistente declinio de la hegemonía estadounidense en el mundo capitalista.

(c) Teorías de las Superpotencias o del conflicto Norte-Sur. A partir del decenio de 1950, comenzaron a aparecer un conjunto propuestas doctrinales que sugerian que las tensiones internacionales eran causadas - principalmente - por el deseo de las dos superpotencias por imponer sea la hegemonía global o en su defecto un virtual condominio hegemónico en el mundo, mediante el disciplinamiento de los respectivos aliados y clientes. Posiblemente, la más famosa de este tipo de elaboraciones doctrinales fue la llamada Teoría de los Tres Mundos, formulada por Mao Zedong. ${ }^{4}$ En término generales, la teoría de los Tres

\footnotetext{
${ }^{4}$ La teoría maoísta de los Tres Mundos tiene como antecedente directo la noción de "zona intermedia", que el propio Mao construyó en la década de 1950 para comprender las tendencias del sistema internacional. La noción de "zona intermedia" terminó siendo particularmente útil en lo que se refiere al estudio de las condiciones y posibilidades de las naciones asiáticas, africanas y latinoamericanas, y su relación con la pugna entre el "imperialismo" estadounidense y el "social-imperialismo" soviético por la hegemonía global. En términos operativos la noción de la "zona intermedia" sugiere que la lucha real entre las superpotencias por la hegemonía global en el contexto de la Guerra Fría no tenia lugar en el teatro europeo, sino en el vasto y diverso conjunto de naciones del Tercer Mundo. En ese sentido, desde la perspectiva maoísta, tanto el imperialismo estadounidense como el socialimperialismo soviético estarían empeñados, primero, en dominar las naciones del Tercer Mundo, para luego, agredirse mutuamente. En el interludio, sin embargo, predominaría un condominio hegemónico favorable para ambas superpotencias, pero
}

Universitas - Relações Int., Brasília, v. 2, n.2, p. 137-167, jul./dez. 2004 
Mundos sugiere que las relaciones internacionales estarían dominadas por la interacción entre tres grupos de naciones (o Mundos). El Primer Mundo estaría conformado por las dos superpotencias (Estados Unidos y la Unión Soviética), ambas empeñadas en alcanzar la hegemonía económica y política de la sociedad internacional o, en su defecto, en imponer un condominio hegemónico global. El Segundo Mundo estaría compuesto por los países industrializados de Europa Occidental, Canadá y Japón. Mientras, el Tercer Mundo estaría compuesto por todos los países en desarrollo (incluída la propia China). De acuerdo con la racionalidad de esta teoría, las naciones del Tercer Mundo, con el apoyo de las naciones del Segundo Mundo, deberían construir una alianza estratégica anti-hegemónica orientada a contener y revertir las aspiraciones imperialistas o neo-coloniales de ambas superpotencias. En otras palabras, las aspiraciones y presiones hegemónicas globales de Washington y Moscú solamente podrían ser controladas y derrotadas mediante la universal y persistente resistencia de las naciones del Tercer y Segundo Mundo. ${ }^{56}$

(d) Teoría de los conflictos Este-Este y Oeste-Oeste. Esta teoría sugiere que la polarización de las relaciones entre los bloques socialista y capitalista, especialmente durante los períodos de

en perjuicio de los intereses de las naciones del Tercer Mundo. La Teoria de los Tres Mundos fue presentada, publicamente, por Deng Xiaoping, en abril de 1974, en la Asamblea General de la ONU.

${ }^{5}$ En 1975 se introdujo una modificación en la Teoría de los Tres Mundos, al afirmarse que si bien ambas superpotencias continuaban con sus aspiraciones hegemónicas, la URSS parecía mucho más amenazadora y agresiva que los Estados Unidos, debido a la derrota militar de ésta en la Segunda Guerra de Indochina y el aparente declinio de su poderío económico y militar. En ese sentido, las naciones del Tercer Mundo deberían resistir con mayor énfasis al así llamado "social imperialismo" soviético.

${ }^{6}$ Variantes más o menos similares a la Teoría de los Tres Mundos fueron planteadas por autores de diferentes fuentes de inspiración doctrinal; incluyendo: marxistas antisoviéticos, "tercer-mundistas" radicales, militantes conservadores y ultranacionalistas, anarquistas, "albaneses", guevaristas, maoístas, dependencistas, entre muchos otros. Todos ellos con el común denominador de atribuir las tensiones internacionales de la Segunda Guerra Fría a las desiguales y conflictivas relaciones entre países con (espurias) aspiraciones hegemónicas globales y países en desarrollo.

Universitas - Relações Int., Brasília, v. 2, n.2, p. 137-167, jul./dez. 2004 
mayor tensión, sería en realidad un mecanismo utilizado por ambas superpotencias para reimponer la hegemonía o disciplinamiento sobre aliados y clientes, dando por hecho que tales aliados $\mathrm{y}$ clientes habían alcanzado un creciente grado de autonomía económica, política y militar durante los períodos de coexistencia pacífica o antagonismo oscilatório de los años 1960 y de distensión o Détente, vigente durante gran parte del decenio de 1970. Desde ésta perspectiva, los investigadores de la historia de la Guerra Fría podrían analizar las divergencias políticas, económicas y estratégicas entre la potencia hegemónica de Occidente, esto es, Estados Unidos, frente a otras naciones dichas "occidentales" en Europa, Asia-Pacífico y América Latina y el Caribe (o conflictos Oeste-Oeste). Por otro lado, los conflictos políticos, económicos y estratégicos entre la potencia hegemónica de la comunidad socialista, quiere decir, la Unión Soviética, frente a los países de Europa del Este y otros estados "orientados al socialismo" (o conflictos Este-Este). En otras palabras, los autores inspirados en esta teoría sostienen que el verdadero conflicto internacional en el contexto de la Guerra Fría debería buscarse en los procesos de disciplinamiento que ambas superpotencias habrían pretendido realizar al interior de ambos bloques políticos, económicos y militares, justificandolo en la agudización de las tensiones en el eje Este-Oeste.

(e) Teoría del control de armamentos. Se sugiere que una considerable cuota de responsabilidad por las tensiones internacionales se podrían atribuir a las tendencias expansivas y autonomistas del poder militar y de los complejos industriales-militares ${ }^{7}$ de las

\footnotetext{
${ }^{7}$ La noción de complejo industrial-militar alude a una coalición de poderosos grupos e instituciones que comparten intereses económicos, políticos y militares orientados a intensificar los gastos de defensa más alla de las reales necesidades de defensa del Estado. Normalmente un complejo industrial-militar se integra por: a) burocracia militar, b) industrias de armamento (públicas, privadas y mixtas), c) autoridades políticas y militares, d) instituciones de ciencia y tecnología vinculados al sector de defensa, y e) exportadores y comerciantes de armamento. La idea del complejo industrial-militar se popularizó, en 1961, cuando el Presidente Eisenhower advirtió públicamente al pueblo y gobierno de los Estados Unidos sobre los peligros de las
}

Universitas - Relações Int., Brasília, v. 2, n.2, p. 137-167, jul./dez. 2004 
grandes potencias. Entre los autores más conocidos de este paradigma sobresale Edward Thompson (1985). Conviene agregar que Thompson (1985) es el creador de la "tesis del exterminismo", donde se advierte de la grave amenaza que representaban la autonomía relativa de los mandos militares responsables por las armas nucleares y la urgente necesidad de luchar por la paz independientemente de las posturas políticas personales, debido a los enormes riesgos que supondría para la humanidad en su conjunto una guerra nuclear total. En este sentido, no es extraño que esta línea de pensamiento haya terminado siendo tan popular entre los movimientos ambientalistas o "verdes" y pacificistas, sobretodo en Europa Occidental.

En suma, es posible constatar la existencia de un conjunto de perspectivas epistemológicas (o paradigmas) desde los cuales es posible aproximarse a los problemas de investigación y al debate académico específico sobre la problemática planteada por la historia de la Guerra Fría. Analizar éstos y otros paradigmas desde la perspectiva de la matriz disciplinaria -entendida como campo de tensión epistémica entre paradigmas activos y en compentencia- es pertinente, puesto que cada una de las posiciones teórico-metodológicas permite apreciar parcialmente la complejidad de los problemas de investigación propios de esta riquísima temática. En otras palabras, se está frente a una matriz disciplinaria compuesta por paradigmas que ofrecen explicación parcial de los acontecimientos mundiales pero que, definitivamente, no logran agotar los variados objetos de estudio de la sub-especialidad. En ese orden de ideas, todas esas posiciones teóricometodológicas son válidas pero ninguna es hegemónica. Todas ellas gozan de un considerable poder explicativo pero también de limitaciones operacionales.

Aún así, dada su expresiva capacidad explicativa o de convocatoria, parece importante reconocer que la Teoría de las Superpotencias es -desde el punto de vista epistemológico particularmente influyente en el presente ensayo. Ello implica, basicamente, que aqui se acepta que la así llamada Guerra Fría terminó

tendencias expansivas e influencias políticas de la poderosa coalición que giraba en torno al complejo militar-industrial estadounidense.

Universitas - Relações Int., Brasília, v. 2, n.2, p. 137-167, jul./dez. 2004 
erigiéndose, para los países en desarrollo -incluyendo los países de la América Latina y el Caribe-, en un perverso mecanismo de disciplinamiento y subordinación a disposición de los sectores dominantes de las superpotencias (y de sus respectivos aliados y clientes en la "periferia") y, consecuentemente, en detrimento de las aspiraciones, de las prioridades y de los intereses nacionales vitales de dichos pueblos.

\section{Requisitos para la construcción de una tesis latinoamericana sobre la lógica de la Guerra Fría}

El proceso de construcción de la noción de "viento del sudoeste" o de la tesis latinoamericana sobre la lógica de la guerra fría demanda, entre otras cosas, definir claramente ciertos requisitos básicos de naturaleza teórico-metodológica que deberan ser cumplidos para garantizar un mínimo de coherencia, racionalidad y rigurosidad. Las tradiciones, doctrinas o tipos ideales de políticas internacionales "candidatas" a formar parte del esquema de análisis, sobretodo aquellas que "pretenden" ser consideradas a formar parte del núcleo duro e irreductible consustancial a la tesis latinoamericana, deberan consecuentemente someterse a una virtual evaluación con base en criterios de identificación y agregación.

En otras palabras, es de crucial importancia para los fines del presente estudio ponderar los criterios que permitan definir cuales tradiciones, doctrinas o tipos ideales de política internacional deben ser consideradas (y cuales no deberan serlo). Dicho criterio de identificación, inclusión y agregación permite presuponer la existencia de: a) un campo de tensión epistémica, concebido esquemáticamente como una figura compuesta de tres círculos concentricos (interior, intermedio y exterior), siendo que los tipos ideales de política internacional más próximos del centro del círculo interior se identificarían de manera más directa con el "viento del sudoeste", y b) cierto número de tradiciones, doctrinas o tipos ideales de política internacional latinoamericana sobre la lógica de la guerra fría (todos ellos activos, verificables y en competencia), siendo que algunas pocas de éstas, por su gran relevancia, pasarían a formar parte del núcleo

Universitas - Relações Int., Brasília, v. 2, n.2, p. 137-167, jul./dez. 2004 
duro e irreductible consustancial al "viento del sudoeste" o tesis latinoamericana (véase Gráfico 1).

Conviene agregar que el núcleo duro e irreductible de política internacional consustancial a la tesis latinoamericana se caracteriza no solamente por estar conformado por la virtual "armonización" de un pequeño y coherente número de tipos ideales de política internacional seleccionados con base en criterios que son enunciados enseguida, como también en un virtual patrón de mensurabilidad o estandar mínimo dado de comparación. En este último sentido, el núcleo duro e irreductible, auxiliado por el campo de tensión epistémica, permitiría identificar o demostrar en que medida otras tradiciones, doctrinas o tipos ideales de política internacional se aproximarían de la tesis latinoamericana sobre la lógica de la guerra fría, sin necesidad de conocer previamente la situación de la inserción internacional del Estado -0 del agente no gubernamental- correspondiente. En otras palabras, entre más próxima del núcleo duro e irreductible pueda identificarse una determinada tradición, doctrina o tipo ideal de política internacional, más "latinoamericanista" podría ser considerada.

Así las cosas, aqui se acepta que durante los años de la guerra fría los "hombres de Estado" encargados de la formulación e implementación de políticas internacionales directamente vinculadas a los desafíos emanados del mundo "bipolar", bien como intelectuales, estrategas y otros "especialistas" de las relaciones internacionales, construyeron diferentes tradiciones, doctrinas o tipos ideales de política que, muchas veces, terminaron inspirando o justificando determinadas opciones en los correspondientes procesos de toma de decisiones. Obviamente, tales opciones de política correspondían a Estados históricamente determinados por "fuerzas profundas" de naturaleza política, económica, social, cultural y estratégica.

Entre tales tradiciones, doctrinas o tipos ideales de política internacional frente a la guerra fría pueden citarse, por ejemplo, la doctrina de las fronteras ideológicas, la tercera vía peronista, el antiimperialismo cubano, la tesis del subimperialismo (o del satélite predilecto), la política externa independiente brasileña, la tesis de Contadora sobre el conflicto regional en América Central, etc. Más aún, muchas de las tradiciones, doctrinas o tipos ideales de política

Universitas - Relações Int., Brasília, v. 2, n.2, p. 137-167, jul./dez. 2004 
internacional latinoamericana sobre la guerra fría fueron influenciadas por construcciones teóricas homólogas formuladas por los "decididores" de las grandes potencias, tales como: la doctrina de la contención del expansionismo soviético, la teoría del imperialismo, el "neutralismo" y la "equidistancia" de los No Alineados, el gaullismo, entre otros (véase Gráfico 1).

Conviene resaltar que tales tradiciones, doctrinas o tipos ideales de política internacional pueden ser estudiadas en el marco del campo de tensión epistémica propuesto. Para tanto, los tipos ideales de política internacional deberían ubicarse en algún punto del esquema formado por los tres círculos concentricos, tomando en cuenta el grado de "proximidad" de tal tipo ideal de política internacional con relación al núcleo duro e irreductible.

A su vez, el núcleo duro e irreductible surge, como dicho, de la virtual "armonización" de un conjunto de tipos ideales que cumplen con los requisitos de expresar una orientación democrática, progresista, solidária, nacionalista y antiintervencionista; todos ellos factores que caracterizan la doble inserción latinoamericana como región identificada esencialmente con los valores occidentales permanentes y con las aspiraciones del mundo en desarrollo (paz, democracia, derechos humanos, economía social de mercado, correcta convivencia, adscripción a los principios básicos del derecho internacional, etc.). Ello es extremadamente importante para los fines del presente estudio dado que se erige en el ethos o fundamento de la tesis latinoamericana y del "viento del sudoeste". Por tanto, es pertinente incluir un breve análisis de cada uno de aquellos criterios.

Orientación democrática y progresista del regimen. La teoria política democrática, desde Aristóteles, sugiere que la Democracia no es solamente un método o un conjunto de procedimientos para seleccionar o identificar los individuos encargados de ejercer el poder político sobre el resto de la población de un determinado território. Ésta concepción formal, elitista o minimalista de la Democracia contrasta de manera notoria con las teorías clásicas o substantivas de la Democracia. Aristóteles, por ejemplo, afirmaba que "la democracia es el gobierno de los más por el bien de los pobres" (citado por Boron,

Universitas - Relações Int., Brasília, v. 2, n.2, p. 137-167, jul./dez. 2004 
1997: 77). Otro conocido autor ponderó que la Democracia es el gobierno del pueblo, por el pueblo y para el pueblo.

Nótese que en su sentido clásico, la noción de Democracia conlleva una inequivoca orientación igualitarista, participativa y substantiva. De hecho, tal democracia deberia desembocar en la "buena sociedad", caracterizada por un profundo sentido liberador, fraterno y anti-autoritario.

En consecuencia, solamente un regimen democrático -en el sentido clásico o aristotélico del término-, orientado claramente hacia la libertad, la justicia, y el progreso económico y social de la población, especialmente de la población en situación de exclusión social, podría reclamar para sí la más alta legitimidad interna. Más aún, para los fines de éste estudio es importante resaltar que solamente regimenes realmente democráticos pueden ser considerados como parte del núcleo duro e irreductible de la tesis latinoamericana sobre la Guerra Fría.

Ello implica, obviamente, la exclusión de una serie de experiencias autoritárias tales como gobiernos dictatoriales de derecha y de izquierda, regimenes burocrático-autoritários, sultanísticos, etc.

Conviene agregar que las cinco experiencias seleccionadas para formar parte del núcleo de la tesis latinoamericana -esto es, la tercera vía peronista, el persistente antiintervencionismo mexicano, la política externa independiente brasileña del período Quadros-Goulart, la así llamada "doctrina Betancourt", y la tesis de Contadora sobre el conflicto regional en América Central- cumplen, unas más que otras, con el criterio del requisito democrático. Ello, teniendo en vista que se trata de regimenes surgidos de procesos electorales libres, transparentes y competitivos, y que, además, procuraron promover el desarrollo económico, político y social de sus pueblos.

Política externa solidária. Tradicionalmente, las políticas internacionales de la mayoría de los Estados latinoamericanos y caribeños durante los años de la Guerra Fría se inspiraron en alguno de los dos paradigmas fundamentales de la historia de las relaciones hemisféricas: el monroismo y el bolivarismo.

En términos generales, el paradigma monroista ha supuesto la existencia de un conjunto de intereses -sean económicos, políticos o

Universitas - Relações Int., Brasília, v. 2, n.2, p. 137-167, jul./dez. 2004 
estratégicos- comunes o convergentes entre los Estados Unidos y las naciones de América Latina y el Caribe. La idea de la solidaridad hemisférica contra potenciales enemigos extra-continentales, especialmente frente a diferentes potencias europeas, ha sido uno de los postulados básicos del paradigma. Hasta aqui, tudo bem! Pero resulta que, en la práctica, el monroismo, que nunca fue bien visto por los países latinoamericanos -con la excepción parcial del caso brasileño-, terminó erigiendose en un virtual velo que pretendía justificar o legitimar las repetidas y abusivas intervenciones estadunidenses -abiertas y encubiertas- en los países localizados en la mitad sur del continente, particularmente en las naciones ubicadas en la cuenca del Caribe.

Peor aún, en el contexto global de la así llamada Guerra Fría, el monroismo, desde la perspectiva de Washington, pasó a significar unilateralismo, solidaridad hemisférica anticomunista (lo que terminó favoreciendo a muchos regimenes dictatoriales de derecha), y, en los hechos, el alineamiento automático con relación a las prioridades estratégicas globales y regionales estadunidenses (Smith, 1994).

Aceptando que el paradigma monroista pasó a implicar alineamiento automático con las prioridades estratégicas de Washington, parece obvio que la política internacional de un Estado latinoamericano influenciado por el monroismo dificilmente podría identificarse con el núcleo duro e irreductible de la tesis latinoamericana sobre la Guerra Fría.

En contraste, el paradigma bolivariano ha promovido persistentemente la necesidad de profundizar los lazos de solidaridad, cooperación e integración exclusivamente entre naciones latinoamericanas y caribeñas -esto es, entre los pueblos de "nuestra América". En general, el paradigma bolivariano pregona el entendimiento y el apoyo mútuo entre pueblos y Estados de la región; condena, simultáneamente, toda forma de intervencionismo, imperialismo, (neo)colonialismo o hegemonismo -sobretodo cuando se trata de aspiraciones y presiones hegemónicas de potencias extraregionales.

En ese sentido, todas aquellas políticas internacionales de países latinoamericanos orientadas hacia el entendimiento, la

Universitas - Relações Int., Brasília, v. 2, n.2, p. 137-167, jul./dez. 2004 
solidaridad y la busqueda de soluciones justas, equilibradas, democráticas y duraderas para los conflictos -domésticos e internacionales-, por un lado, y de oposición frente a las pretensiones hegemónicas de los "dos imperialismos", por otro, terminaron identificandose con el paradigma bolivariano.

En suma, durante los perturbadores años de la Guerra Fría, el paradigma bolivariano continuó implicando tanto solidaridad y cooperación intra-regional, como no alineamiento y oposición frente a las (espúrias) aspiraciones y presunciones hegemónicas de los "dos imperialismos" -especialmente del "imperialismo" más próximo y conocido.

Conviene agregar que solamente aquellas políticas inspiradas en el paradigma bolivariano podrían ser consideradas para formar parte del núcleo de la tesis latinoamericana sobre la Guerra Fría. Naturalmente, ello excluye aquellas políticas inspiradas en el monroismo, en lo que teóricos chinos llamaban "social-imperialismo" soviético, y en otras formulaciones y doctrinas de política internacional semejantes.

Nacionalismo económico. Durante los perturbadores años de la Guerra Fría, muchos actores sociales, políticos y económicos especialmente aquellos de orientación progresista- postulaban la doble necesidad de acelerar el desarrollo económico y la lucha por liberación nacional de los pueblos del mundo en desarrollo.

Guiados por el ideal de conquistar un desarrollo nacional -en general, dentro del sistema capitalista- tales actores insistían en la necesidad de alcanzar: (a) una mayor independencia política y equidistancia frente a los "dos imperialismos" de la época, (b) creciente autonomía con relación al control económico externo, (c) la eliminación de la tradicional opresión interna, mediante procesos de reforma y/o de revolución social, y (d) la (re)creación y valorización de una nueva cultura nacional. Para los fines del presente estudio el inciso de letra " $b$ " es particularmente relevante, dado que refiere específicamente a la problemática del nacionalismo económico y, en términos más amplios, a la economía política del desarrollo.

Efectivamente, resulta de gran relevancia constatar que fue, justamente, durante los años de la guerra fría cuando muchos pueblos

Universitas - Relações Int., Brasília, v. 2, n.2, p. 137-167, jul./dez. 2004 
del mundo en desarrollo -sobretodo en aquellos pueblos de mayor desarrollo relativo- comenzaron a cuestionar tanto el tradicional orden económico internacional, como las políticas inspiradas en el liberalismo económico, la considerable penetración del capitalismo internacional y, en general, la -insatisfactoria- división internacional del trabajo.

El tradicional orden económico internacional fue cuestionado no solamente por autores de inspiración marxista y neoclásica, sino también por analistas de orientación estructuralista. Todos ellos preocupados, en mayor o menor intensidad, con los desafíos colocados por la interdependencia asimetrica, el subdesarrollo y la dependencia. En el caso de la América Latina, la discusión sobre las condiciones y posibilidades del nacionalismo económico y de la economía política del desarrollo fue extremadamente fecunda. El surgimiento de la tradición estructuralista, estrechamente vinculada a funcionários de la Comisión Económica para América Latina (CEPAL), fue particularmente significativa y de impacto duradero.

Conviene recalcar que Prebisch, Furtado, Sunkel y otros estructuralistas ponderaban la necesidad de impulsar un modelo de desarrollo nacional con creciente grado de autonomía, mayor productividad e inclusión social. Ello suponía, siguiendo a Keynes y Manoilescu (Love, 1998), fomentar la industrialización, intensificar las capacidades regulatorias del Estado en la economía, cuestionar la lógica inherente al esquema centro-periferia, promover la integración regional, estimular la difusión de ciencia y tecnologia, apoyar procesos de desarrollo social, etc.

Esta temática es importante para los fines del presente estudio por varias razones: en primer lugar, es posible verificar una relación de "afinidad electiva" -en el sentido weberiano del término- entre el nacionalismo económico, el paradigma estructuralista y las políticas internacionales independientes (o no alineadas); en otras palabras, es posible prever cierta articulación entre el pensamiento económico estructuralista y la tesis latinoamericana sobre la guerra fría, teniendo al nacionalismo-desarrollista como referente común. En segundo lugar, la formulación de proyectos nacionales de desarrollo capitalista -bajo el ideal de la economía social de mercado- generó consensos

Universitas - Relações Int., Brasília, v. 2, n.2, p. 137-167, jul./dez. 2004 
estratégicos entre sectores progresistas y nacionalistas de la burguesía, sindicalistas, clases medias, fuerzas armadas, intelectuales, burocracia estatal, y otros grupos; en caso de acceder al poder tales alianzas o consensos estratégicos normalmente terminaban adoptando políticas exteriores convergentes con el núcleo duro de la tesis latinoamericana sobre la guerra fría.

Por esas y otras razones que no pueden ser analizadas con el necesario detalle en el presente estudio, parece obvio que las experiencias de nacionalismo-desarrollista, especialmente aquellas de orientación estructuralista, terminaron repercutiendo de manera directa e indirecta en la inserción internacional de las naciones latinoamericanas y caribeñas. Más aún, parece claro que el pensamiento económico estructuralista -en contraste con las escuelas de pensamiento económico neoclásico y marxista-, dada su originalidad, pertinencia y relevancia, es compatible con lo pregonado por la tesis latinoamericana sobre la guerra fría.

Antiintervencionismo. Naturalmente existe una incompatibilidad evidente, categórica y definitiva entre la tesis latinoamericana sobre la Guerra Fría, por un lado, y lógicas y políticas de orientación intervencionista, imperialista o neocolonialista, por otro. Si las políticas compatibles con la tesis latinoamericana se pautaban por los principios fundamentales del derecho internacional especialmente en lo referente a la autodeterminación de los pueblos y a la no intervención en los asuntos internos de otros Estados-, sus contrapartes se caracterizaban justamente por lo contrario, quiere decir, por la amenaza, por el uso de la fuerza, por la agresión (abierta o encubierta) y por otras políticas semejantes. Ello fue muy claro y evidente en varios casos que ocurrieron en el subcontinente, incluyendo la agresión contra Guatemala (en 1954), Cuba (desde 1960), República Dominicana (en 1965), Chile (entre 1970-1973), Nicaragua (entre 1980-1990), Granada (1983), entre otros casos; sin olvidar el apoyo de grandes potencias a dictaduras militares (especialmente de derecha). En ese sentido, vale resaltar las ponderaciones del presidente mexicano Miguel de la Madrid Hurtado, durante su visita a Brasília, en marzo de 1984 - quiere decir, durante la fase de bipolaridad rígida de la Segunda Guerra Fría -,

Universitas - Relações Int., Brasília, v. 2, n.2, p. 137-167, jul./dez. 2004 
El ejercicio de una política exterior de principio no es, en el mundo contemporáneo, simple insistencia retórica ni, aún menos, deseo de ignorar la realidad política internacional. [...] Es, sobre todo, guía permanente para conocerla y reaccionar ante ella y es, también, oportunidad de modificarla, en función de los intereses de la paz y la cooperación internacional.

Postular la no intervención, no equivale a ignorar una deplorable realidad y violaciones al derecho internacional: injerencias directas e indirectas, acciones de desestabilización y agresiones abiertas; equivale, en cambio, a recordar que su estricta observancia es requisito central para modificarla y establecer un ámbito para el ejercicio de la autodeterminación. Insistir en la renuncia al uso y a la amenaza de la fuerza, no equivale a desconocer la preocupante frecuencia con que se acude a la violencia para dirimir las diferencias internacionales; equivale, en cambio, a señalar que los conflictos, localizados encierran un aterrador potencial de extensión y generalización, por lo que aumentan el riesgo de una guerra nuclear.

Defender la soberanía es, ante todo, fórmula para señalar que las acciones de los poderosos, deben tener como valladar el respeto escrupuloso al espacio geográfico y a la identidad nacional de cada uno, elementos esenciales de la igualdad jurídica de los estados. Buscar la transformación, en favor del desarrollo, del inequitativo esquema de relaciones económicas internacionales, no es intento de imponerse sobre las realidades de la economía mundial, sino reconocer que son ellas mismas las que imponen la necesidad de un funcionamiento más equitativo, armónico y compartido. ${ }^{8}$

Al mismo tiempo, parece pertinente agregar que las alegadas y oscilatórias pretensiones "subimperiales" de ciertos países latinoamericanos -específicamente de Argentina, Brasil y Cuba -

8 "Discursos dos Presidentes do Brasil, João Figueiredo, e do México, Miguel de la Madrid Hurtado, no Palácio do Itamaraty, em Brasília, em 29 de março de 1984, por ocasião de jantar oferecido pelo Presidente brasileiro ao Presidente mexicano", Resenha de Política Externa do Brasil, N 40; pp. 35-44.

Universitas - Relações Int., Brasília, v. 2, n.2, p. 137-167, jul./dez. 2004 
también son contrarias al espíritu y a la filosofía subyacente a la tesis latinoamericana.

En suma, de lo dicho se desprende que el núcleo duro e irreductible de la tesis latinoamericana es compatible unicamente con regimenes y políticas de clara, evidente y definitiva orientación democrática, progresista, solidária, nacionalista y antiintervencionista. Consecuentemente, se postula que el núcleo duro e irreductible de política internacional subyacente a la tesis latinoamericana debería surgir como resultado de la armonización y convergencia de criterios de al menos cinco tradiciones, doctrinas o tipos ideales: la tercera vía peronista, el persistente antiintervencionismo mexicano, la política externa independiente brasileña del período Quadros-Goulart, la así llamada "doctrina Betancourt", y la tesis de Contadora sobre el conflicto regional en América Central (véase Gráfico 1).

Notese que se trata de un conjunto de políticas que surgieron de la inserción internacional individual o colectiva de gobiernos que, efectivamente, demostraron orientación democrática, progresista, solidária, nacionalista y antiintervencionista -aunque reconociendo que, eventualmente, algunas de tales políticas pudieron ser abandonadas por gobiernos subsiguientes del mismo Estado. Obviamente, se trata de tipos ideales de política que postulaban una buena o correcta convivencia internacional -fundamentada, como mínimo, en la adscripción de las partes al derecho intenacional y al paradigma bolivariano de solidaridad, comprensión y cooperación intra-latinoamericana y caribeña.

Más aún, los tipos ideales de política en cuestión propugnaban no solamente por una relación no alineada, equidistante y equilibrada frente a las aspiraciones hegemónicas de los "dos imperialismos" de la época ó por una acción político-diplomática solidaria y concertada entre Estados latinoamericanos, sino que también impulsaban -o al menos eran convergentes con- un cambio social, económico y político favorable a los intereses, prioridades y aspiraciones de las clases trabajadoras (muchas veces sujetas a estructuras de poder excluyentes, injustas, autoritárias e inmorales). He ahí el ethos o fundamento del

Universitas - Relações Int., Brasília, v. 2, n.2, p. 137-167, jul./dez. 2004 
"viento del sudoeste" o de la tesis latinoamericana sobre la lógica de la guerra fría.

Por estas y otras razones el núcleo duro e irreductible de política internacional consustancial a la tesis latinoamericana debe ubicarse en el centro del círculo interno del campo de tensión epistémica propuesto. Dicho núcleo duro e irreductible vendría a eregirse en patrón de mensurabilidad o en estandar mínimo dado de comparación. En otras palabras, terminaría siendo un importantísimo componente de una (futura) teoría latinoamericana sobre la lógica de la guerra fría.

Adicionalmente, el círculo interior del campo de tensión epistémica podría ser enriquecidos por otras tradiciones, doctrinas o tipos ideales de política internacional latinoamericana que cumplen con los requisitos centrales supracitados, pero que aún no forman parte del núcleo duro e irreductible. Entre esas otras tradiciones o tipos ideales vale citar, por ejemplo, el "figuerismo" liberal-democrático costarricense -incluyedo sus desdoblamientos correspondientes al proceso negociador de Esquipulas-, la Operación Panamericana propuesta por el gobierno del Presidente Juscelino Kubitschek, la doctrina del "pluralismo político americano" impulsado por el gobierno del Presidente Salvador Allende Gossens, el regionalismo cepalino -especialmente en lo relacionado a la integración económica, entre otros. Ciertamente, tales tipos ideales de política internacional no solamente merecen ser colocadas en el círculo interior del campo de tensión epistémica, como también son fuertes "candidatas" a integrar de hecho el núcleo duro e irreductible de política internacional consustancia a la tesis latinoamericana sobre la lógica de la guerra fría (véase Gráfico 1).

El círculo intermedio del campo de tensión epistémica se presenta integrado por un grupo de tradiciones, doctrinas o tipos ideales de política formuladas e implementadas en la región para encarar los desafíos emanados de la lógica de competencia, confrontación y tensión propia de la guerra fría, pero que al ser confrontadas con los requisitos básicos supracitados demostraron carecer de las virtudes de sus homólogas ubicadas en el círculo interior.

Universitas - Relações Int., Brasília, v. 2, n.2, p. 137-167, jul./dez. 2004 
En los hechos, se trata de doctrinas de política internacional implementadas principalmente por gobiernos autoritários -de naturaleza pretoriana, despótica, tradicionalista, marxista-leninista, o burocrático-autoritária-, que muy poco contribuyen al debate sobre la posición latinoamericana y caribeña frente a la lógica de la guerra fría en la medida que muchas de ellas eran casi siempre "reflejos" de las prioridades e intereses estratégicos de los "dos imperialismos" y/o de los correspondientes socios, aliados o clientes en el subcontinente. ${ }^{9}$ Entre tales tipos ideales de política internacional vale señalar las siguientes: a) la tesis del subimperialismo (o del satélite privilegiado), b) la doctrina de la seguridad nacional y de las fronteras ideológicas, c) la tesis de la "exportación de la revolución" (por ejemplo, el caso de OLAS), d) la teoría del dominó, e) el así llamado "pragmatismo" argentino-brasileño de fines del decenio de 1970, entre otras (véase Gráfico 1).

Entretanto, en el círculo exterior del campo de tensión epistémica podrían ubicarse las tradiciones, doctrinas o tipos ideales de política internacional global de las grandes potencias -algunas de las cuales con expresivos vínculos e intereses de naturaleza económica, política o estratégica en la América Latina y el Caribe. Tales tipos ideales de política, a pesar de no haber sido creados en la región, terminaron influyendo de manera significativa en la formulación e implementación de políticas internacionales de diferentes Estados latinoamericanos. Por tal razón parece importante incluirlas en el análisis.

En esa línea, considerase que los principales tipos ideales de política internacional que forman parte del círculo externo son: a) la teoría de la contención del expansionismo soviético, b) la teoría del imperialismo, incluyendo las doctrinas de la coexistencia pacífica y de la correlación global de fuerzas, c) la teoría de los Tres Mundos,

\footnotetext{
${ }^{9}$ La política internacional "pragmática" de ciertos Estados burocrático-autoritários, especialmente en los casos argentino y brasileño, aunque siendo muy interesantes y perturbadores, no aplican al núcleo duro e irreductible debido a la muy corta legitimidad y solvencia ético-moral. Vale insistir en la necesidad historica de que la tesis latinoamericana sobre la guerra fría sea construida con base en experiencias de política internacional democrática, progresista, solidária, nacionalista y antiintervencionista.
}

Universitas - Relações Int., Brasília, v. 2, n.2, p. 137-167, jul./dez. 2004 
propuesta por Mao Zedong, d) el gaullismo francés, e) el paradigma neomonroista (incluyendo el corolario Kennan/Kirkpatrick de la doctrina Monroe y la doctrina Reagan), y f) el neutralismo activo y equidistante frente a los "dos imperialismos" propugnado por el movimiento de los No Alineados (especialmente en su vertiente "titoista").

Vale insistir que tales tradiciones de política internacional global de las grandes potencias interactuban entre sí y con sus homólogas de los otros dos círculos concentricos. En el fondo se trata de una compleja relación dialéctica que, ciertamente, no dejó de influir en la formulación e implementación de las políticas exteriores latinoamericanas durante los perturbadores años de la guerra fría.

Universitas - Relações Int., Brasília, v. 2, n.2, p. 137-167, jul./dez. 2004 
Gráfica 1: Campo de tensión epistémica, integrado por políticas internacionales, teniendo como punto de referencia el núcleo duro e irreductible de la tesis latinoamericana sobre la guerra fría

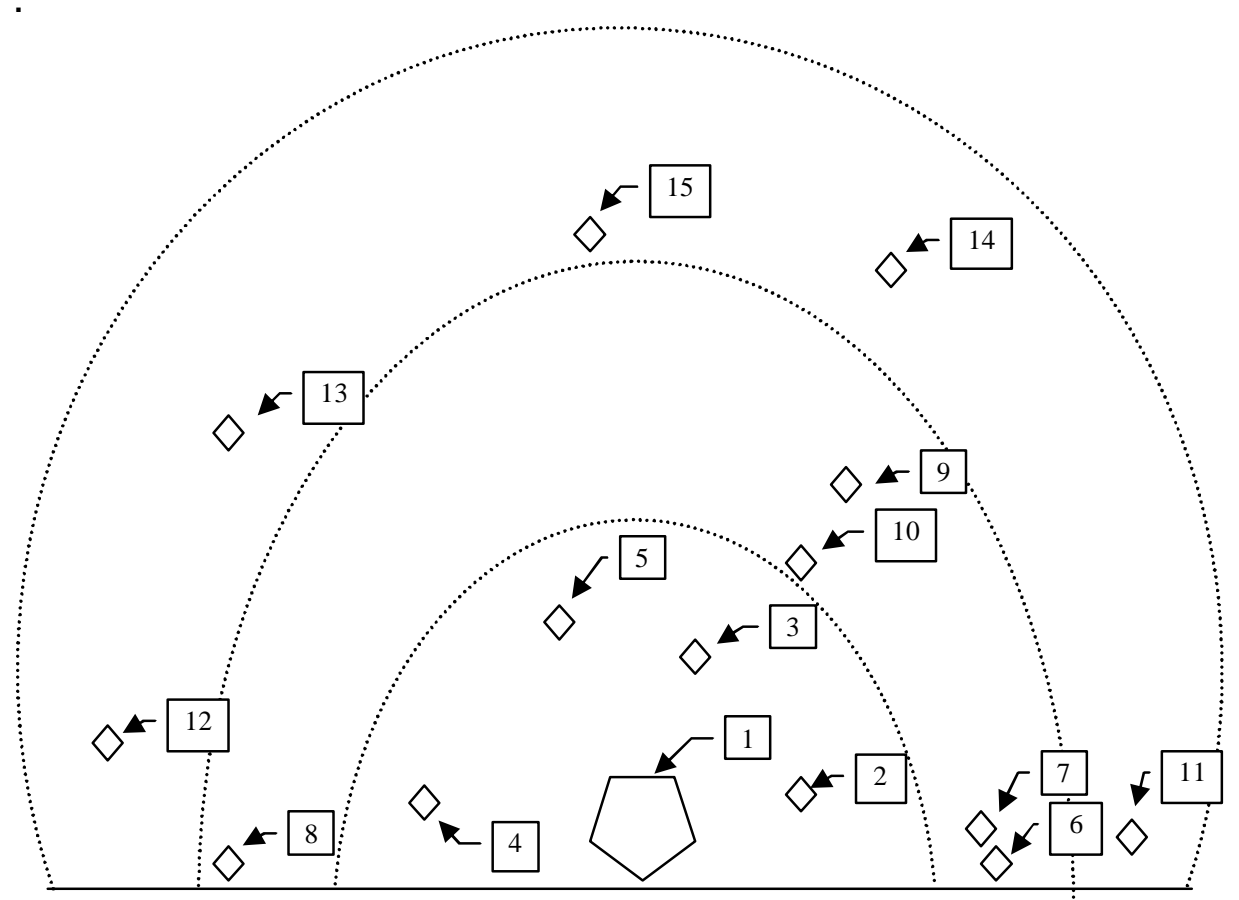

Leyenda: 1) Núcleo duro e irreductible consustancial a la tesis latinoamericana, 2) Figuerismo, 3) Operación Panamericana, 4) Pluralismo político, 5) Regionalismo cepalino, 6) Tesis del subimperialismo, 7) Doctrina de la seguridad nacional y de las fronteras ideológicas, 8) Tesis de la "exportación de la revolución" (OLAS), 9) Teoría del dominó, 10) Pragmatismo argentino-brasileño, 11) Teoría de la contención, 12) Teoría del imperialismo, 13) Teoría de los Tres Mundos, 14) Gaullismo, 15) Neutralismo activo

Universitas - Relações Int., Brasília, v. 2, n.2, p. 137-167, jul./dez. 2004 


\section{Consideraciones finales}

La historia de las relaciones internacionales durante la segunda mitad del siglo XX presenta como uno de los fenómenos centrales aquello a lo que, convencionalmente, terminó llamandose como la guerra fría.

Conviene insistir que la noción de guerra fría no alude solamente a la competencia, confrontación y tensión entre las superpotencias y sistemas sociales antagónicos de la época, como normalmente se sostiene. Dicho fenómeno también se expresó a través de: a) conflictos al interior de las diferentes sociedades, b) divergencias entre las superpotencias y sus respectivos aliados (conflictos OesteOeste y Este-Este), y c) entre las superpotencias y las naciones en desarrollo, incluyendo el caso específico de América Latina y el Caribe, que es el que más interesa para los fines del presente estudio (conflictos Norte-Sur, sobre la base de la teoría de las superpotencias).

Al mismo tiempo, constatase que la literatura especializada disponible sobre sobre la temática en cuestión es claramente insuficiente y poco satisfactoria. Desafortunadamente, la literatura disponible sobre la posición y conducta de los pueblos y Estados latinoamericanos y caribeños frente a la lógica de la guerra fría es inexplicablemente escasa -nótese que no fue posible localizar texto académico consistente y reciente alguno sobre la temática-, y lo poco que existe está casi siempre inspirado en teorías, doctrinas o tradiciones importadas, que difícilmente pueden ser asumidas por especialistas latinoamericanos, por motivos que no es posible abordarlos con el debido detalle en este artículo.

De hecho es posible que buena parte de las dificultades, limitaciones e insuficiencias de los estudios sobre la historia de la guerra fría en la región se deban, justamente, a la carencia de una perspectiva de análisis propia, anti-hegemónica y de clara e inequívoca orientación democrática, progresista, nacionalista, solidária y antiintervencionista. En otras palabras, parece claro que los estudios latinoamericanos sobre la guerra fría han penado por la ausencia de aproximaciones equivalentes a lo que fueron, por ejemplo, el pensamiento cepalino y la teoría de la dependencia para los estudios

Universitas - Relações Int., Brasília, v. 2, n.2, p. 137-167, jul./dez. 2004 
interdisciplinários sobre el desarrollo, o la teologia de la liberación para las aproximaciones de los sectores progresistas de la Iglesia católica latinoamericana interesados en los problemas socio-religiosos del subcontinente.

Si ello es realmente así, el presente estudio pretende revitalizar el debate y propone alternativas para construir una aproximación teórico-metodológica más satisfactoria, pertinente, rigorosa e históricamente verificable sobre la posición de los pueblos y Estados latinoamericanos y caribeños frente a los desafios planteados por la historia de la guerra fría.

En términos generales, la propuesta aqui presentada, que necesariamente debe tener un fuerte contenido teórico y especulativo, presupone la existencia tanto de un campo de tensión epistémica (esquemáticamente integrado por tres círculos concentricos), como de un regular número de tradiciones, doctrinas o tipos ideales de política internacional. Siendo que algunas de tales tradiciones, doctrinas o tipos ideales de política internacional, por cumplir ciertos requisitos -entre otros: orientación democrática, progresista, solidária, nacionalista y antiintervencionista-, dan lugar, conjuntamente, a lo que aqui se llama de núcleo duro e irreductible de política consustancial a la tesis latinoamericana sobre la lógica de la guerra fría. En ese sentido, el núcleo duro e irreductible erigese en patrón de mensurabilidad o estandar mínimo dado de comparación. Y, por la misma razón, se localiza en el centro del círculo interior del campo de tensión epistémica. El núcleo duro e irreductible propuesto se integra por la armonización y convergencia de criterios propios de: la tercera vía peronista, el antiintervencionismo mexicano, la política externa independiente brasileña del período Quadros-Goulart, la doctrina Betancourt y la tesis de Contadora sobre el conflicto regional en América Central.

Entretanto, el círculo intermedio esta compuesto por tradiciones, doctrinas o tipos ideales de política internacional que también son importantes en el estudio del impacto de la lógica de la guerra fría en la América Latina y el Caribe, pero que por diferentes razones no cumplen con los requisitos centrales citados. Lo mismo

Universitas - Relações Int., Brasília, v. 2, n.2, p. 137-167, jul./dez. 2004 
sucede con las políticas externas propugnadas por las grandes potencias que forman parte del círculo exterior.

El esquema de análisis presentado debe ser entendido, vale subrayar, en el marco de un campo de tensión epistémica en el cual interactuan, de manera dialéctica, las diferentes formulaciones supracitadas. En ese sentido, se trata de un esquema de equilibrio inestable. Ello implica, entre otras cosas, reconocer su carácter dinámico, aceptar que nuevos tipos ideales de política internacional puedan ser incorporados, desagregados y/o redefinidos - inclusive en el núcleo duro e irreductible, siempre y cuando tales tipos ideales adscriban al ethos y cumplan con los requisitos fundamentales colocados -, y aceptar que todo lo aqui expuesto deberá ser sometido al rigor de la comprobación y convalidación histórica

Por último, es importante reafirmar que uno de los objetivos del estudio es revitalizar el debate latinoamericano sobre la lógica y las políticas propias de la guerra fría. Consecuentemente, si el artículo logra contribuir en el relanzamiento de dicho debate - a partir de un nuevo, rigoroso y más alto nivel de comprensión -, ciertamente, habrá conseguido alcanzar uno de sus objetivos primários y fundamentales.

\section{Referências Bibliográficas}

AYERBE, Luis Fernando (2001): Estados Unidos e América Latinal A construção da hegemonia, São Paulo: Editora UNESP.

BLACK, Jan Knippers (1986): Sentinels of Empire/ The United States and Latin American Militarism, Wesport (EUA): Greenwood Press.

BORON, Atilio (1997): Estado, Capitalismo y Democracia en América Latina, $3^{\mathrm{a}}$ ed., Buenos Aires: Universidad de Buenos Aires.

CASTAÑEDA, Jorge (1996): “América Latina y la terminación de la Guerra Fría: Un ensayo sobre la frustración”, en Abraham F. Lowenthal y Gregory F. Treverton (compiladores): América Latina en un mundo nuevo, trad. de Eduardo L. Suárez, Ciudad de México: Fondo de Cultura Económica; pp. 40-69.

Universitas - Relações Int., Brasília, v. 2, n.2, p. 137-167, jul./dez. 2004 
CERVO, Amado Luiz (2001): Relações Internacionais da América Latina/ Velhos e novos paradigmas, Brasília: IBRI/Fundação Alexandre Gusmão.

y Clodoaldo BUENO (2003): História da política exterior do Brasil, Coleção o Brasil e o Mundo, Brasília: Editora da Universidade de Brasília e IBRI.

CHOMSKY, Noam (2003): Contendo a democracia, Rio de Janeiro: Record.

(2002): El terror como política exterior de Estados Unidos, Buenos Aires: Libros del Zorzal. (1997): World Orders, Old and New, Londres: Pluto Press. (1996): O que o Tio Sam realmente quer, Brasília: Editora Universidade de Brasília. (1985): "Armas estratégicas, Guerra Fria e Terceiro Mundo", en Edward Thompson y otros: Exterminismo e Guerra Fria, São Paulo: Editora Brasiliense, pp. 188-205.

, Jonathan STEELE, y John GITTINGS (1985): Superpotencias en Colisión/ La nueva guerra fría de los años ochenta, Madrid: Editorial Debate.

GARCÉS, Joan (2000): Soberanos e intervenidos/ Estrategias globales, americanos y españoles, $2^{\text {a }}$ ed., Madrid: Siglo Veintiuno de España Editores.

GONZÁLEZ CASANOVA, Pablo (1995): América Latina: Historia de medio siglo, vol. 1 y 2, Ciudad de México: Siglo XXI Editores y UNAM.

HALLIDAY, Fred (1986): The Making of the Second Cold War, $2^{\mathrm{a}}$ ed., Londres: Verso.

LaFEBER, Walter (1991): America, Russia, and the Cold War 19451990, $6^{\text {a }}$ ed., New York: McGraw-Hill.

LOVE, Joseph (1998): A Construção do Terceiro Mundo/ Teorias do Subdesenvolvimento na Romênia e no Brasil, Rio de Janeiro: Paz e Terra.

MONIZ BANDEIRA, Luiz (1999): Relações Brasil-Estados Unidos no contexto da globalização/ II - Rivalidade Emergente, $2^{\mathrm{a}}$ ed., São Paulo: Editora SENAC São Paulo.

Universitas - Relações Int., Brasília, v. 2, n.2, p. 137-167, jul./dez. 2004 
(1998): De Martí a Fidel/ A Revolução Cubana e a América Latina, Rio de Janeiro: Civilização Brasileira.

(1993): Estado Nacional e Política Internacional na América Latina/ O Continente nas Relações Argentina-Brasil (1930-1992), São Paulo: Editora Ensaio/EDUNB.

PARKINSON, F. (1974): Latin America, The Cold War, \& The World Powers 1945-1973, Berverly Hills: Sage.

RODMAN, Peter (1994): More precious than peace/ The Cold War and the Struggle for the Third World, New York: Charles Scribner's Sons.

ROUQUIÉ, Alain (1997): América Latina/ Introducción al Extremo Occidente, $4^{\mathrm{a}}$ ed., Ciudad de México: Siglo XXI Editores.

SCHOULTZ, Lars (2000): Estados Unidos: poder e submissão/ Uma história da política norte-americana em relação à América Latina, Bauru: Editora da Universidade do Sagrado Coração (EDUSC).

(1987): National Security and United States Policy toward Latin America, Princeton: Princeton University Press.

SHULMAN, Marshall, ed. (1986): East-West Tensions in the Third World; New York: The American Assembly/W.W. Norton \& Company.

SMITH, Gaddis (1994): The last years of the Monroe Doctrine 19451993, New York: Hill and Wang.

STEPHANSON, Anders (1996): "Fourteen Notes on the very concept of the Cold War", Nueva York: Columbia University; em Internet: [www2.h-net.msu.edu/ diplo/stephanson.html].

THOMPSON, Edward (1985): "Notas sobre o exterminismo, o estágio final da civilização", en Edward Thompson e outros: Exterminismo e Guerra Fria, São Paulo: Editora Brasiliense, pp. $15-57$.

WOOD, Bryce (1985): The Dismantling of the Good Neighbor Policy, Austin: University of Texas Press.

Universitas - Relações Int., Brasília, v. 2, n.2, p. 137-167, jul./dez. 2004 